\title{
Treadmill exercise ameliorates social isolation-induced memory impairment by enhancing silent information regulator-1 expression in rats
}

\author{
Tae-Woon Kim ${ }^{1,2}$, Sang-Seo Park', Mal-Soon Shin ${ }^{3}$, Hye-Sang Park ${ }^{4}$, Seung-Soo Baek ${ }^{2, *}$ \\ 'Department of Physiology, College of Medicine, Kyung Hee University, Seoul, Korea \\ 2Department of Sport \& Health Care, College of Art \& Culture, Sangmyung University, Seoul, Korea \\ ${ }^{3}$ School of Global Sport Studies, Korea University, Sejong, Korea \\ ${ }^{4}$ Department of Kinesiology, College of Public Health and Cardiovascular Research Center, Lewis Katz School of Medicine, Temple University, Philadelphia, PA, USA
}

The effect of treadmill exercise on the social isolation-induced memory impairment in relation with the silent information regulator-1 (SIRT-1) was investigated. The rats in the control groups lived four in the standard cages for 8 weeks. The rats in the social isolation groups lived alone in the small cages for 8 weeks. The rats in the treadmill exercise groups were subjected to run on a treadmill for 30 min once a day for 8 weeks. We used step-through avoidance test for short-term memory and Morris water maze task for spatial working memory. Immunohistochemistry for SIRT-1 and western blot analysis for Bax, Bcl-2, cleaved caspase-3, brain-derived neurotrophic factor (BDNF), and tropomyosin receptor kinase $B(T r k B)$ were performed. The rats in the social isolation group showed a decrease in short-term memory and spatial working memory. Treadmill exercise alleviated short-term memory and spatial working memory in the social isolation rats. SIRT-1 expression in the hippocampus was decreased in the rats of social isolation group. Treadmill exercise increased SIRT-1 expression in the social isolation rats. Bax expression was increased, Bcl-2 expression was decreased, and cleaved caspase-3 expression in the hippocampus was increased in the rats of social isolation group. Treadmill exercise decreased Bax expression, increased $\mathrm{Bcl}-2$ expression, and decreased cleaved caspase-3 expression in the social isolation rats. Hippocampal BDNF and TrkB expression was decreased in the rats of social isolation group. Treadmill exercise increased BDNF and TrkB expression in the social isolation rats.

Keywords: Social isolation, Treadmill exercise, Silent information regulator-1, Apoptosis, Brain-derived neurotrophic factor

\section{INTRODUCTION}

Social isolation is a one-dimensional concept that can be defined as a lack of social integration (Hawton et al., 2011). Long-term social isolation causes stress, anxiety, and depression, leading to cognitive impairment and serious morbidity (Chida et al., 2006). Rodents have been widely used to assess developmental change in the fear and stress-related behaviors, and can exhibit a number of behavioral changes including anxiety response, decreased cognitive function, decreased motor activity, and aggressive behavior (Hefner and Holmes, 2007). During adolescence, the rats in the social isolation showed anxiety, depression, and short-term memory impairment, while swimming exercise relieved anxiety, depression, and short-term disability (Park et al., 2020).

Silent information regulator-1 (SIRT-1) is a deacetylating enzyme that is affected by nicotinamide adenine dinucleotide (NAD), reflecting changes in the energy levels of cells. It is effective in retarding aging and is especially important for the management of biological tissue homeostasis. SIRT-1 is involved in the development and regulation of various processes such as cell growth, apoptosis, and repair of DNA damage (Lalla and Donmez, 2013). Calorie restriction and exercise were used to activate

\footnotetext{
*Corresponding author: Seung-Soo Baek (iD https://orcid.org/0000-0002-1340-2098 Department of Sport \& Health Care, College of Art \& Culture, Sangmyung University, 20 Hongjimun 2-gil, Jongno-gu, Seoul 03016, Korea

E-mail: ssoop@smu.ac.kr

Received: April 27, 2020 / Accepted: May 28, 2020
}

This is an Open Access article distributed under the terms of the Creative Commons Attribution Non-Commercial License (https://creativecommons.org/licenses/by-nc/4.0/) which permits unrestricted non-commercial use, distribution, and reproduction in any medium, provided the original work is properly cited. 
SIRT-1, and activation of SIRT-1 delayed cell aging and provided a neuroprotective effect (Ramis et al., 2015). Exercise increased the level of NAD and activated the NAD-dependent deacetylase activity of SIRT-1.

Apoptosis is a form of cell death that serves to remove dying cells from cell proliferating or differentiating, thus apoptosis plays an important role in normal development and tissue homeostasis. However, inappropriate or excessive apoptosis is associated with neurological disorders (Lee et al., 2003). Bcl-2 family is classified into anti-apoptotic proteins and pro-apoptotic proteins according by function. Bcl-2, an antiapoptotic protein, is known to regulate apoptotic pathways and protect against cell death. Bax, a pro-apoptotic protein of that family, is expressed abundantly and selectively during apoptosis and promotes cell death (Song et al., 2018). Activation of caspases is another important characteristic of apoptosis, and caspase- 3 is a main performer of apoptosis (Song et al., 2018).

Hippocampal brain-derived neurotrophic factor (BDNF) is known to be increased by learning and exercise (Hall et al., 2000; Park et al., 2019). Exercise-induced BDNF expression increases neurogenesis and enhances long-term potentiation of the hippocampus (Farmer et al., 2004). Exercise has been reported to improve neurological disorders caused by various types of brain damages. Treadmill exercise increased expression of BDNF and tropomyosin receptor kinase B (TrkB) (Park et al., 2019).

Many hippocampal neurons were significantly increased in the exercised rats, suggesting that regular aerobic exercise exerted beneficial effect on cognitive function (Uysal et al., 2005). Relationship between exercise and SIRT-1 activation under social isolation condition has not been well established. In this study, we investigated the effect of treadmill exercise on social isolation-memory impairment in relation with SIRT-1.

\section{MATERIALS AND METHODS}

\section{Experiment animals}

This study was approved by the Kyung Hee University Institutional Animal Care and Use Committee in Seoul, Korea (KHUASP [SE]-16-154). Male Wistar rats (48 weeks old) were used for this experiment. Rats were randomly divided into four groups ( $n=8$ per group): control group, control and exercise group, social isolation group, social isolation, and exercise group.

\section{Social isolation protocol}

Social isolation was conducted by previously described method (Amiri et al., 2015). The rats in the control groups lived four in the standard cages $(26 \mathrm{~cm} \times 42 \mathrm{~cm} \times 18 \mathrm{~cm})$ for 8 weeks. The rats in the social isolation groups lived alone in the small cages $(20 \mathrm{~cm} \times$ $26 \mathrm{~cm} \times 13 \mathrm{~cm}$ ) for 8 weeks.

\section{Exercise protocol}

The rats in the treadmill exercise groups were subjected to run on a treadmill for 30 min once a day for 8 weeks. Exercise load consisted of warm-up at a speed of $3 \mathrm{~m} / \mathrm{min}$ for the first $5 \mathrm{~min}$, at a speed of $8 \mathrm{~m} / \mathrm{min}$ for last $25 \mathrm{~min}$, with the $0^{\circ}$ inclination.

\section{Step-through avoidance test}

Step-through avoidance test was performed. The rats were placed on a $7 \times 25$-cm platform with a height of $2.5 \mathrm{~cm}$, and then allowed to rest on platform for $2 \mathrm{~min}$. Platform faced a $42 \times 25-\mathrm{cm}$ grid of parallel $0.1-\mathrm{cm}$ caliber steel bars, which were spaced $1 \mathrm{~cm}$ apart. In training session, the rats received a 1-mA scramble foot shock for 2 sec immediately upon stepping down. Latency time (second) in each group was measured at $2 \mathrm{hr}$ after training session. Latency over $300 \mathrm{sec}$ was counted as $300 \mathrm{sec}$.

\section{Morris water maze task}

Morris water maze task was performed. Training test consisted of three trials each day for 6 consecutive days. During each trial, the rats were placed in water facing the wall of maze in one of three quadrants that did not contain platform. Probe trial was performed at $24 \mathrm{hr}$ after the end of the 6 days of training. Percentage of time spent in the target quadrant was considered as an indicator of memory performance.

\section{Tissue preparation}

The animals were sacrificed immediately after determination of Morris water maze task. The animals were fully anesthetized Zoletil $50(10 \mathrm{mg} / \mathrm{kg}$, intraperitoneally; Vibac Laboratories, Carros, France). The rats were transcardially perfused with $50 \mathrm{mM}$ phosphate-buffered saline and then fixed with freshly prepared solution of $4 \%$ paraformaldehyde in $100 \mathrm{mM}$ phosphate buffer $(\mathrm{pH}$, 7.4). Brains were then removed, postfixed in same fixative overnight, and transferred into a $30 \%$ sucrose solution. Coronal sections with thicknesses of $40 \mu \mathrm{m}$ were made using a freezing microtome (Leica, Nussloch, Germany).

\section{Immunohistochemistry for SIRT-1}

To visualize SIRT-1 expression, immunohistochemistry for SIRT-1 in the hippocampal CA1 and dentate gyrus was performed. Sections were selected from each brain and incubated overnight 
with human anti-SIRT-1 antibody (1:200; Santa Cruz Biotechnology, Santa Cruz, CA, USA), then with biotinylated mouse secondary antibody (1:200; Vector Laboratories, Burlingame, CA, USA) for another $1 \mathrm{hr} 30 \mathrm{~min}$. Secondary antibody was amplified with Vector Elite ABC kit (1:100; Vector Laboratories). Antibody-biotin-avidin-peroxidase complexes were visualized using $0.03 \%$ diaminobenzidine, and sections were mounted onto gelatin-coated slides. Slides were air-dried overnight at room temperature, and coverslips were mounted using Permount (Thermo Fisher Scientific, Waltham, MA, USA).

\section{Western blotting for BDNF, TrkB, Bax, Bcl-2, and cleaved caspase-3}

Hippocampus tissues were homogenized on ice and lysed in a lysis buffer containing $50 \mathrm{mM}$ Tris- $\mathrm{HCl}(\mathrm{pH}, 7.5), 150 \mathrm{mM}$ $\mathrm{NaCl}, 0.5 \%$ deoxycholic acid, $1 \%$ Nonidet $\mathrm{P} 40,0.1 \%$ sodium dodecyl sulfate (SDS), $1 \mathrm{mM}$ PMSF, and 100-mg/mL leupeptin. Protein content was measured using a Bio-Rad colorimetric protein assay kit (Bio-Rad, Hercules, CA, USA). Protein of $30 \mu \mathrm{g}$ was separated on SDS-polyacrylamide gels and transferred onto a nitrocellulose membrane, which was incubated with mouse $\beta$-actin antibody (1:2,000; Santa Cruz Biotechnology), mouse Bcl-2 antibody (1:1,000; Santa Cruz Biotechnology), rabbit BDNF antibody (1:1,000; Santa Cruz Biotechnology), rabbit TrkB antibody (1:1,000; Cell Signaling Technology, Beverly, MA, USA), rabbit Bax antibody (1:1,000; Cell Signaling Technology) and rabbit cleaved caspase-3 antibody (1:1,000; Cell Signaling Technology). Horseradish peroxidase-conjugated anti-mouse for $\beta$-actin, $\mathrm{Bcl}-2$, and anti-rabbit for BDNF, TrkB, Bax, cleaved caspase- 3 were used as the secondary antibodies.

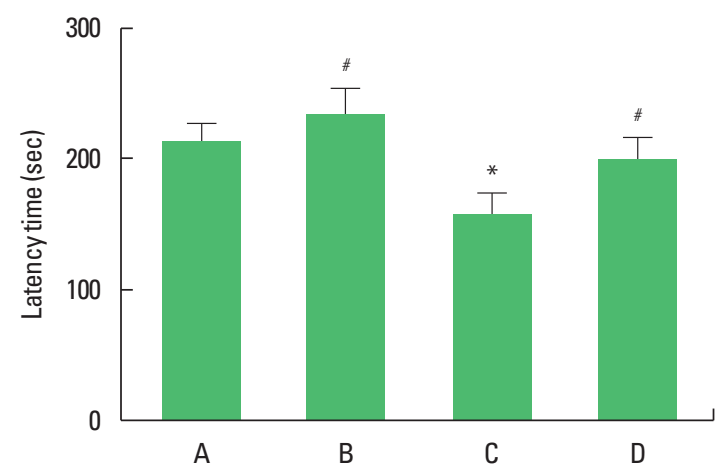

\section{Data analysis}

For confirming expression of BDNF, TrkB, Bax, Bcl-2, cleaved caspase-3, detected bands were calculated densitometrically using Molecular Analyst TM, version 1.4.1. Number of SIRT-1-positive cells in dentate gyrus was counted hemilaterally under a light microscope (Olympus, Tokyo, Japan). Data were analyzed with oneway analysis of variance and then Duncan post-hoc tests. All values are expressed as the mean \pm standard error of mean, and $P$-value $<0.05$ was considered significant.

\section{RESULTS}

\section{Short-term memory and spatial working memory}

We used step-through avoidance test for short-term memory and Morris water maze task for spatial working memory (Fig. 1). Latency of the social isolation group was shorted than the control group $(P<0.05)$. Treadmill exercise lengthened latency in the rats of the social isolation group $(P<0.05)$. Time in probe quadrant of the social isolation group was shorted than the control group $(P<0.05)$. Treadmill exercise lengthened time in probe quadrant in the rats of the social isolation group $(P<0.05)$.

\section{SIRT-1-positive cells in hippocampus}

Number of SIRT-1-positive cells in the hippocampus was counted (Fig. 2). Number of SIRT-1-positive cells in the hippocampal CA1 and dentate gyrus of the social isolation group was decreased than the control group $(P<0.05)$. Treadmill exercise increased numbers of SIRT-1-positive cells in the rats of the social isolation group $(P<0.05)$.

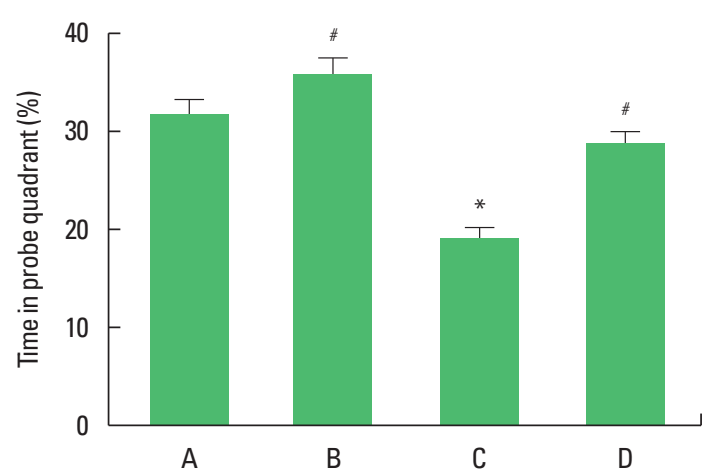

Fig. 1. The effects of treadmill exercise on the short-term memory in step-through test (left panel) and spatial working memory in Morris water maze task (right panel). A, control group; $B$, control and exercise group; $C$, social isolation group; $D$, social isolation and exercise group. The data are presented as the mean \pm standard error of the mean. ${ }^{*} P<0.05$ compared to the control group. ${ }^{\#} P<0.05$ compared to the social isolation group. 

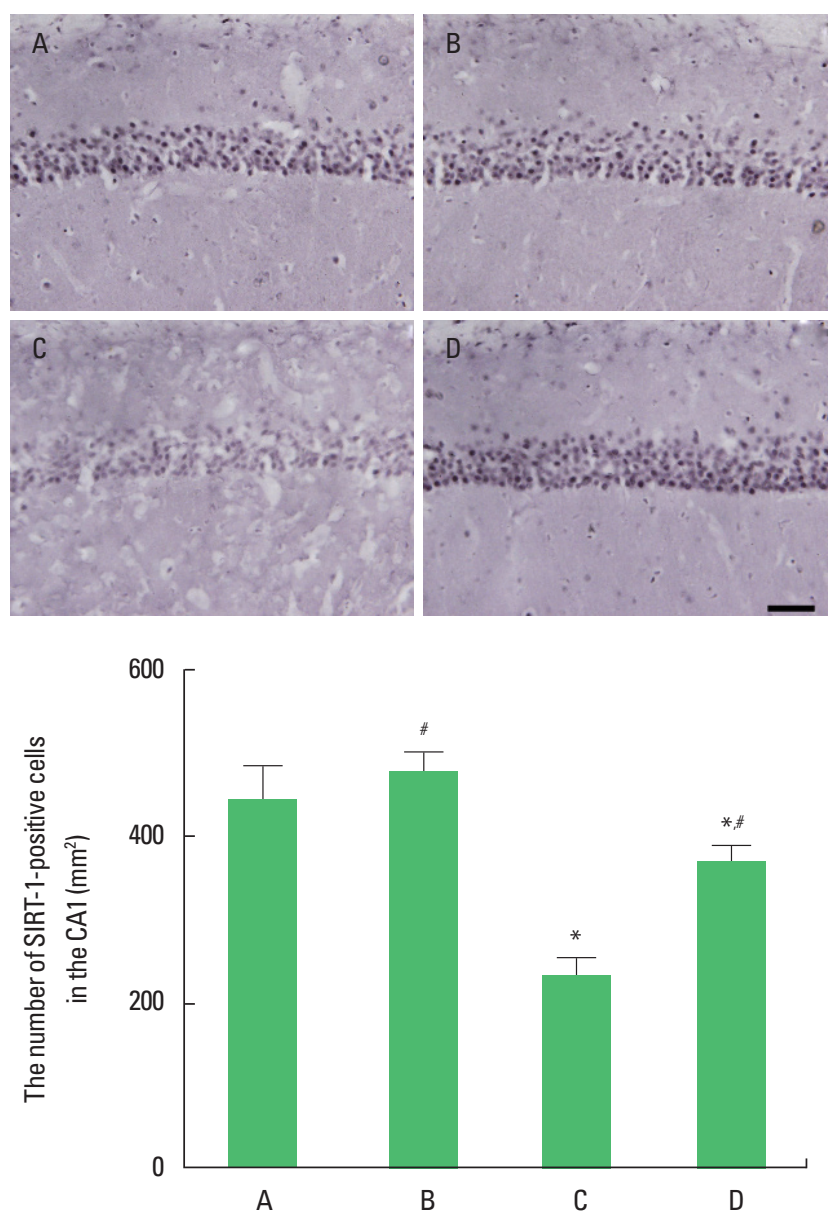
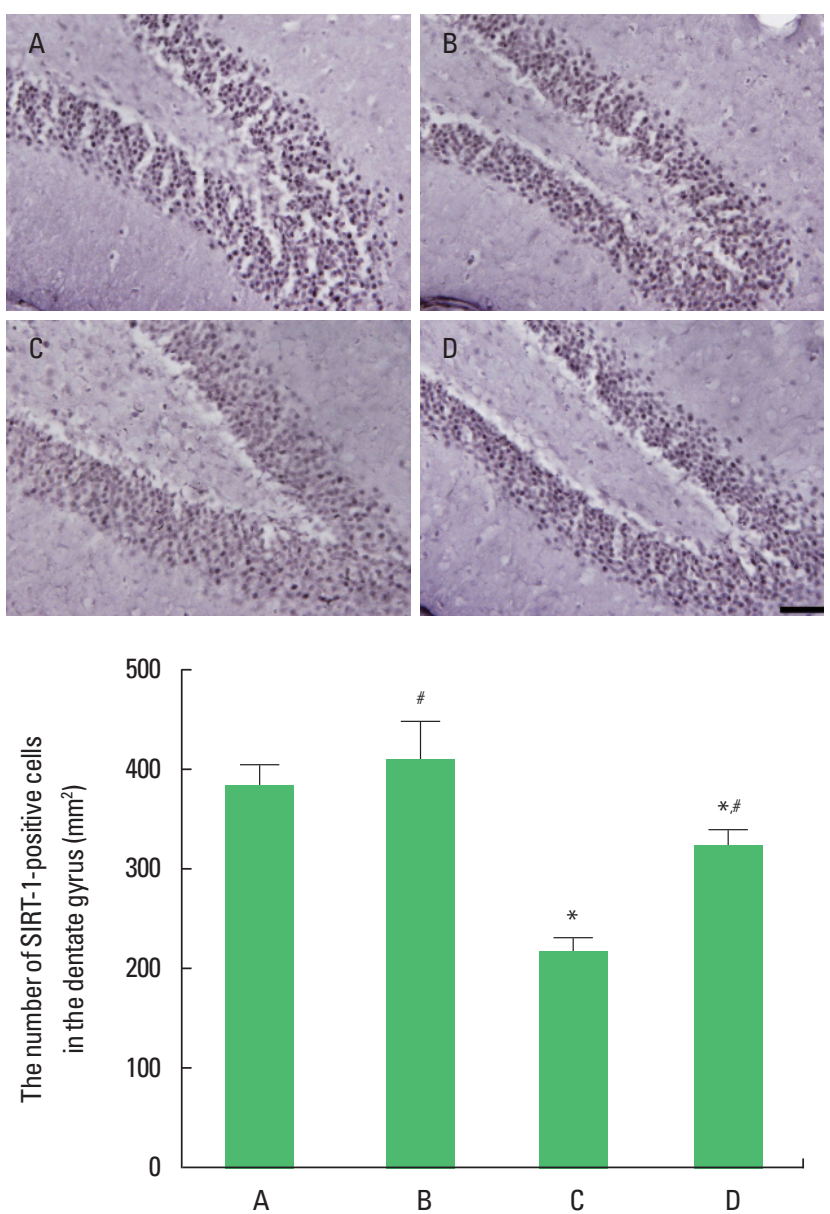

Fig. 2. The effects of treadmill exercise on silent information regulator-1 (SIRT-1)-positive cells. Upper panel: immunohistochemistry of SIRT-1-positive cells in the hippocampal CA1 (left) and dentate gyrus (right). Lower panel: the number of SIRT-1-positive cells in the hippocampal CA 1 (left) and dentate gyrus (right). The scale bar represents $50 \mu \mathrm{m}$ in each group. A, control group; B, control and exercise group; $C$, social isolation group; $D$, social isolation and exercise group. The data are presented as the mean \pm standard error of the mean. ${ }^{*} P<0.05$ compared to the control group. ${ }^{*} P<0.05$ compared to the social isolation group.

\section{Bax, Bcl-2, and cleaved caspase-3 expression in the hippocampus}

Expression of Bax, Bcl-2, and cleaved caspase- 3 in the hippocampus was analyzed (Fig. 3). Expression of Bax and cleaved caspase- 3 was increased $(P<0.05)$ and expression of $\mathrm{Bcl}-2$ was decreased in the rats of the social isolation group than the control group $(P<0.05)$. Treadmill exercise decreased expression of Bax and cleaved caspase- $3(P<0.05)$ and increased expression of $\mathrm{Bcl}-2$ in the rats of the social isolation group $(P<0.05)$.

\section{BDNF and TrkB expression in the hippocampus}

Expression of BDNF and TrkB was analyzed (Fig. 4). Expression of $\mathrm{BDNF}$ and $\mathrm{TrkB}$ was decreased in the rats of the social isolation group than the control group $(P<0.05)$. Treadmill exercise increased expression of BDNF and $\operatorname{TrkB}$ in the rats of the social isolation group $(P<0.05)$.

\section{DISCUSSION}

Novel object recognition and fear conditioning were significantly impaired in the social isolation mice (Võikar et al., 2005). Social isolation reduced neurogenesis in the hippocampal dentate gyrus and impaired spatial memory in rodents (Ibi et al., 2008). In this study, the rats in the social isolation group showed a decrease in short-term memory and spatial working memory compared to the control rats. In contrast, treadmill exercise alleviated short-term memory and spatial working memory in the social isolation rats.

SIRT-1 provides cellular stress resistance by inhibiting apoptosis transcription factor p53 and forkhead (Bordone and Guarente, 

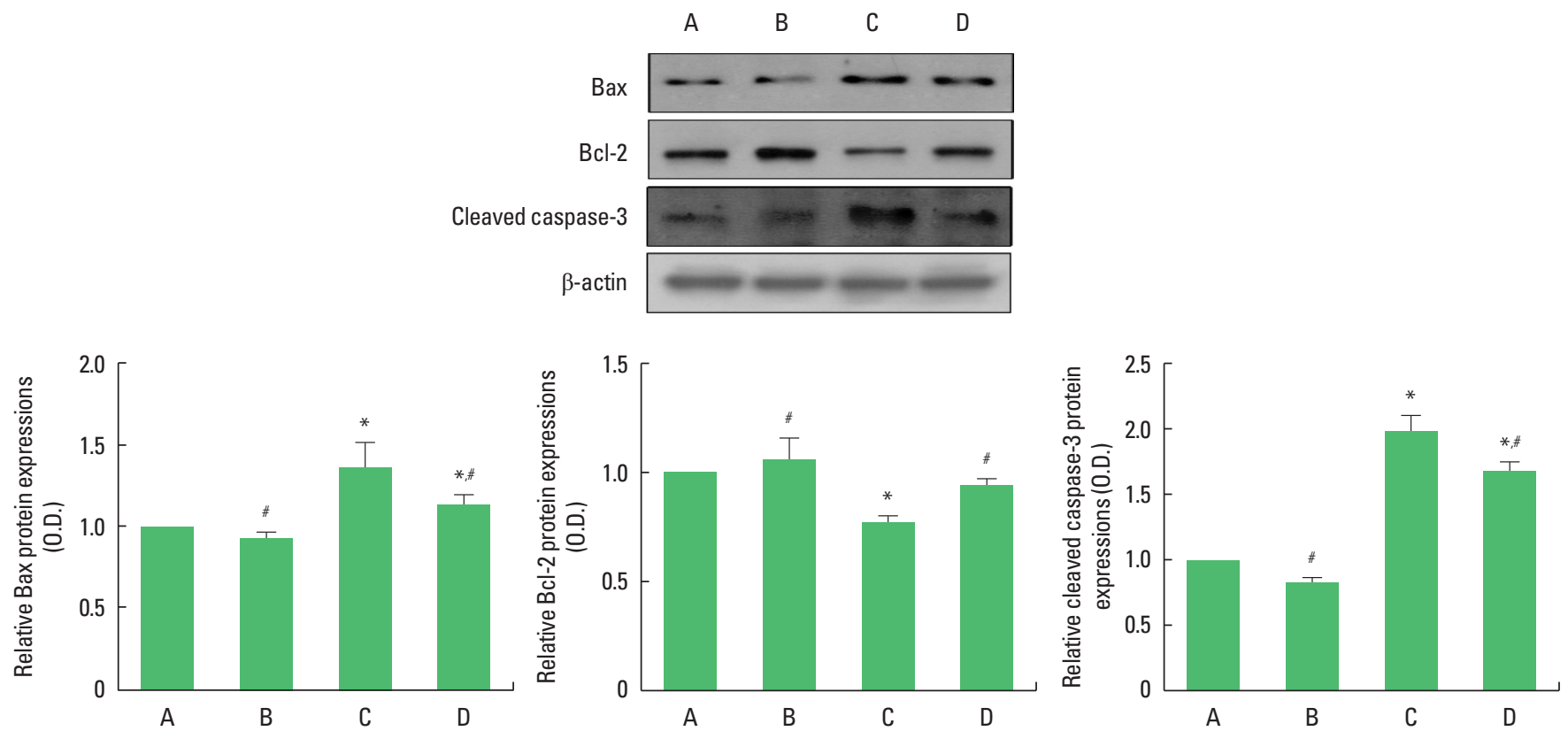

Fig. 3. The effects of treadmill exercise on Bax, Bcl-2, and cleaved caspase-3 protein expression in the hippocampus. Upper panel: representative expression of Bax, Bcl-2, and cleaved caspase-3. Lower panel: relative expression of Bax (left), Bcl-2 (middle), and cleaved caspase-3 (right) in each group. A, control group; B, control and exercise group; $\mathrm{C}$, social isolation group; $\mathrm{D}$, social isolation and exercise group. The data are presented as the mean \pm standard error of the mean. ${ }^{*} P<0.05$ compared to the control group. ${ }^{\#} P<0.05$ compared to the social isolation group.
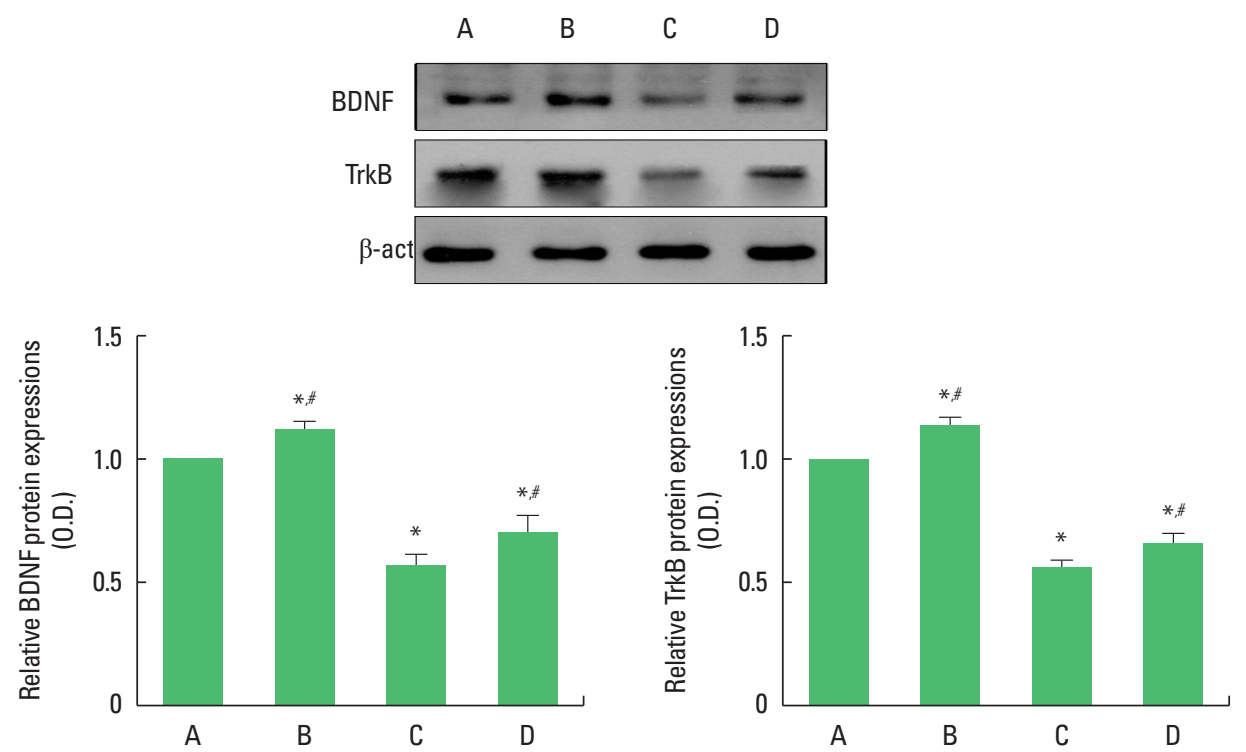

Fig. 4. Effects of treadmill exercise on brain-derived neurotrophic factor (BDNF) and tyrosine kinase B (TrkB) expressions in the hippocampus. Upper panel: representative expression of BDNF and TrkB. Lower panel: relative expression of BDNF (left) and TrkB (right). A, Sham-operation group; B, sham-operation and treadmill exercise group; $\mathrm{C}$, traumatic brain injury (TBI)-induced group; $\mathrm{D}$, TBI-induced and treadmill exercise group. ${ }^{*} P<0.05$ compared to the sham-operation group. ${ }^{\#} P<0.05$ compared to the TBI-induced group.

2005). In addition, SIRT-1 has been shown to mobilize fat by inhibiting peroxisome proliferative-activating receptor in white adipose tissue (Bordone and Guarente, 2005). Caloric restriction and exercise activate adenosine monophosphate-activated protein kinase, and then SIRT-1 is activated in many tissues (Ruderman et al., 2010). Aging inhibits specific activity of SIRT-1 in cerebellum, 
which interferes with motor function. (Marton et al., 2010). Regular exercise reduced detrimental effects of aging process through SIRT-1-dependent pathways (Koltai et al., 2010). Physical exercise improved mitochondrial function of brain cortex and cerebellum, and decreased oxidative stress and apoptosis-related markers (Marques-Aleixo et al., 2015). In this study, SIRT-1 expression in the hippocampus was decreased in the rats of the social isolation group compared to the control rats. In contrast, treadmill exercise increased SIRT-1 expression in the social isolation rats.

Social isolation and chronic unpredictable mild stress showed depressive behavior and exhibited mixed apoptosis/autophagy characteristics (Wang et al., 2019). Social isolation rats during adolescence showed increased in Bax expression and decreased in $\mathrm{Bcl}-2$ expression compared to the group-housed rats (Park et al., 2020). In this study, Bax expression was increased, Bcl-2 expression was decreased, and cleaved caspase- 3 expression in the hippocampus was increased in the rats of the social isolation group compared to the control rats. In contrast, treadmill exercise decreased Bax expression, increased $\mathrm{Bcl}-2$ expression, and decreased cleaved caspase- 3 expression in the social isolation rats.

Regular exercise improved cognitive function and affected brain neuroplasticity and neuronal growth (Radák et al., 2001). Exercise is a special form of stress in that it is predictable and spontaneous, and other forms of psychological and physiological stress are unpredictable, uncontrollable, and have a marked effect on behavior and synaptic plasticity (Wosiski-Kuhn and Stranahan, 2012). It is thought that increased expression of BDNF and TrkB influenced cognitive function by treadmill exercise in the social isolation group. Compared to the rats that received 2 per cage, isolated rats had a significantly reduced BDNF concentration in the hippocampus, while no change was observed in other brain regions examined such as prefrontal cortex and striatum (Scaccianoce et al., 2006). BDNF and TrkB expression in the hippocampus was suppressed in the social isolation rats (Park et al., 2020). In this study, hippocampal BDNF and TrkB expression were decreased in the rats of the social isolation group compared to the control rats. In contrast, treadmill exercise increased BDNF and TrkB expression in the social isolation rats.

Exercise activated SIRT-1, and then promoted learning and memory formation through BDNF-dependent manner (El Hayek et al., 2019). Exercise enhanced SIRT-1 expression, then suppressed apoptosis and enhanced BDNF expression, resulting in memory improvement. Therefore, exercise can be used as a therapeutic strategy to improve memory function that has been impaired by social isolation.

\section{CONFLICT OF INTEREST}

No potential conflict of interest relevant to this article was reported.

\section{ACKNOWLEDGMENTS}

This work was supported by the Ministry of Education of the Republic of Korea and National Research of Foundation of Korea (NRF-2017S1A5A2A01026488).

\section{REFERENCES}

Amiri S, Haj-Mirzaian A, Rahimi-Balaei M, Razmi A, Kordjazy N, Shirzadian A, Ejtemaei Mehr S, Sianati H, Dehpour AR. Co-occurrence of anxiety and depressive-like behaviors following adolescent social isolation in male mice; possible role of nitrergic system. Physiol Behav 2015;145:38-44.

Bordone L, Guarente L. Calorie restriction, SIRT1 and metabolism: understanding longevity. Nat Rev Mol Cell Biol 2005;6:298-305.

Chida Y, Sudo N, Mori J, Kubo C. Social isolation stress impairs passive avoidance learning in senescence-accelerated mouse (SAM). Brain Res 2006;1067:201-208

El Hayek L, Khalifeh M, Zibara V, Abi Assaad R, Emmanuel N, Karnib N, El-Ghandour R, Nasrallah P, Bilen M, Ibrahim P, Younes J, Abou Haidar E, Barmo N, Jabre V, Stephan JS, Sleiman SF. Lactate mediates the effects of exercise on learning and memory through SIRT1-dependent activation of hippocampal brain-derived neurotrophic factor (BDNF). J Neurosci 2019;39:2369-2382.

Farmer J, Zhao X, van Praag H, Wodtke K, Gage FH, Christie BR. Effects of voluntary exercise on synaptic plasticity and gene expression in the dentate gyrus of adult male Sprague-Dawley rats in vivo. Neuroscience 2004;124:71-79.

Hall J, Thomas KL, Everitt BJ. Rapid and selective induction of BDNF expression in the hippocampus during contextual learning. Nat Neurosci 2000;3:533-535.

Hawton A, Green C, Dickens AP, Richards SH, Taylor RS, Edwards R, Greaves CJ, Campbell JL. The impact of social isolation on the health status and health-related quality of life of older people. Qual Life Res 2011;20:57-67.

Hefner K, Holmes A. Ontogeny of fear-, anxiety- and depression-related behavior across adolescence in C57BL/6J mice. Behav Brain Res 2007; 176:210-215.

Ibi D, Takuma K, Koike H, Mizoguchi H, Tsuritani K, Kuwahara Y, Kamei H, Nagai T, Yoneda Y, Nabeshima T, Yamada K. Social isolation rear- 
ing-induced impairment of the hippocampal neurogenesis is associated with deficits in spatial memory and emotion-related behaviors in juvenile mice. J Neurochem 2008;105:921-932.

Koltai E, Szabo Z, Atalay M, Boldogh I, Naito H, Goto S, Nyakas C, Radak Z. Exercise alters SIRT1, SIRT6, NAD and NAMPT levels in skeletal muscle of aged rats. Mech Ageing Dev 2010; 131:21-28.

Lalla R, Donmez G. The role of sirtuins in Alzheimer's disease. Front Aging Neurosci 2013;5:16.

Lee MH, Kim H, Kim SS, Lee TH, Lim BV, Chang HK, Jang MH, Shin MC, Shin MS, Kim CJ. Treadmill exercise suppresses ischemia-induced increment in apoptosis and cell proliferation in hippocampal dentate gyrus of gerbils. Life Sci 2003;73:2455-2465.

Marques-Aleixo I, Santos-Alves E, Balça MM, Rizo-Roca D, Moreira PI, Oliveira PJ, Magalhães J, Ascensão A. Physical exercise improves brain cortex and cerebellum mitochondrial bioenergetics and alters apoptotic, dynamic and auto(mito)phagy markers. Neuroscience 2015;301: 480-495.

Marton O, Koltai E, Nyakas C, Bakonyi T, Zenteno-Savin T, Kumagai S, Goto S, Radak Z. Aging and exercise affect the level of protein acetylation and SIRT1 activity in cerebellum of male rats. Biogerontology 2010;11:679-686.

Park HS, Kim TW, Park SS, Lee SJ. Swimming exercise ameliorates mood disorder and memory impairment by enhancing neurogenesis, serotonin expression, and inhibiting apoptosis in social isolation rats during adolescence. J Exerc Rehabil 2020;16:132-140.

Park SS, Shin MS, Park HS, Kim TW, Kim CJ, Lim BV. Treadmill exercise ameliorates nicotine withdrawal-induced symptoms. J Exerc Rehabil 2019;15:383-391.

Radák Z, Kaneko T, Tahara S, Nakamoto H, Pucsok J, Sasvári M, Nyakas C, Goto $S$. Regular exercise improves cognitive function and decreases oxidative damage in rat brain. Neurochem Int 2001;38:17-23.

Ramis MR, Esteban S, Miralles A, Tan DX, Reiter RJ. Caloric restriction, resveratrol and melatonin: role of SIRT1 and implications for aging and related-diseases. Mech Ageing Dev 2015;146-148:28-41.

Ruderman NB, Xu XJ, Nelson L, Cacicedo JM, Saha AK, Lan F, Ido Y. AMPK and SIRT1: a long-standing partnership? Am J Physiol Endocrinol Metab 2010;298:E751-E760.

Scaccianoce S, Del Bianco P, Paolone G, Caprioli D, Modafferi AM, Nencini $\mathrm{P}$, Badiani A. Social isolation selectively reduces hippocampal brainderived neurotrophic factor without altering plasma corticosterone. Behav Brain Res 2006;168:323-325.

Song SH, Jee YS, Ko IG, Lee SW, Sim YJ, Kim DY, Lee SJ, Cho YS. Treadmill exercise and wheel exercise improve motor function by suppressing apoptotic neuronal cell death in brain inflammation rats. J Exerc Rehabil 2018;14:911-919.

Uysal N, Tugyan K, Kayatekin BM, Acikgoz O, Bagriyanik HA, Gonenc S, Ozdemir D, Aksu I, Topcu A, Semin I. The effects of regular aerobic exercise in adolescent period on hippocampal neuron density, apoptosis and spatial memory. Neurosci Lett 2005;383:241-245.

Võikar V, Polus A, Vasar E, Rauvala H. Long-term individual housing in C57BL/6J and DBA/2 mice: assessment of behavioral consequences. Genes Brain Behav 2005;4:240-252.

Wang M, Bi Y, Zeng S, Liu Y, Shao M, Liu K, Deng Y, Wen G, Sun X, Zeng P, Jing L, Lv Z. Modified Xiaoyao San ameliorates depressive-like behaviors by triggering autophagosome formation to alleviate neuronal apoptosis. Biomed Pharmacother 2019;111:1057-1065.

Wosiski-Kuhn M, Stranahan AM. Opposing effects of positive and negative stress on hippocampal plasticity over the lifespan. Ageing Res Rev 2012;11:399-403. 